\title{
A decade into Facebook: where is psychiatry in the digital age?
}

\author{
Dr Becky Inkster ${ }^{1,2,3} *$, Dr David Stillwell ${ }^{4}$, Dr Michal Kosinski ${ }^{5}$, Prof Peter Jones ${ }^{1,2,3}$ \\ ${ }^{1}$ Department of Psychiatry, University of Cambridge \\ ${ }^{2}$ Wolfson College, University of Cambridge \\ ${ }^{3}$ Cambridgeshire \& Peterborough NHS Foundation Trust \\ ${ }^{4}$ Judge Business School, University of Cambridge \\ ${ }^{5}$ Graduate School of Business, Stanford University \\ * Corresponding Author
}

Keywords: social media, social networking sites, digital footprint, Facebook, friendship, adolescence, mental health, psychiatry, research, identification, intervention, prediction, prevention.

\section{Word count: 1832}

\section{Tables \& Figures: 0 \& 1}

Acknowledgements: We would like to acknowledge Dr Nicholas Simons for his valuable discussions related to this manuscript. Dr Simons has contacted the editorial team directly to confirm his permission. 


\section{Introduction}

Social networking sites are a part of everyday life for over a billion people worldwide. They show no sign of declining popularity, with social media use increasing at 3 times the rate of other Internet use. ${ }^{1}$ Despite this proliferation, mental healthcare has yet to embrace this unprecedented resource. We argue that social networking site data should become a high priority for psychiatry research and mental healthcare delivery.

We illustrate our views using the world's largest social networking site, Facebook, which currently has over 1 billion daily users $^{2}$ ( 1 in 7 people worldwide). Facebook users can create personal profiles, socialize, express feelings, and share content, which Facebook stores as time-stamped digital records dating back to when the user first joined. Evidence suggests that $92 \%$ of adolescents go online daily ${ }^{3}$ and disclose considerably more about themselves online than offline. ${ }^{4}$ Thus, working with Facebook data could further our understanding of the onset and early years of mental illness, a crucial period of interpersonal development. ${ }^{5}$ Furthermore, a diminishing 'digital divide' has allowed for a broader sociodemographic to access Facebook, including homeless youth ${ }^{6}$, young veterans ${ }^{7}$, immigrants, patients with mental health problems $s^{8,9}$, and seniors ${ }^{10}$, enabling greater contact with traditionally harder-to-reach populations.

\section{Personal View}

While acknowledging that issues are far from settled about the role that social media should play in mental health, we argue that it should no longer be a debate about whether researchers and healthcare providers engage with social networking sites, but rather how best to utilize this technology to promote positive change. We discuss how Facebook data can advance psychiatry research and how user-level data could potentially enhance the clinical delivery of personalized patient care. More specifically, we illustrate how Facebook data can assist with identification, intervention, and possibly prediction and prevention of mental illness.

\section{Social Media \& Advancing Psychiatric Research}

\section{Identification}

To what extent might Facebook measures improve detection of mental health factors? We address this question by implementing a novel online-offline framework that combines Facebook data with pre-existing offline longitudinal cohort information (Figure 1). This approach presents several opportunities to improve detection. Facebook data (i) tends to be more reliable than offline self-reported information ${ }^{11,12}$, (ii) often reflects valid depictions of offline behaviours (e.g., 
Facebook alcohol displays indicate actual misuse ${ }^{13}$ ), (iii) measures content difficult to assess offline (e.g. conversation intensity), (iv) potentially generates novel online measures, (v) achieves previously inconceivable sample sizes ${ }^{14}$ and (vi) is cost-effective. ${ }^{12}$ Furthermore, having access to offline clinical outcomes and behavioural measures frames the meaning of novel, undefined Facebook measures. Offline validation could improve the quality of online data and guide prioritization of online parameter selection. Pairing sensitive online-offline health data is feasible, with a recent study reporting that $71 \%$ of participants consented to sharing their social networking site data (primarily Facebook) and having it linked with their electronic medical records. ${ }^{15}$

\section{Facebook Data Collection}

Provided that participant consent is obtained ${ }^{12}$, numerous Facebook measures can be collected for data analysis, which have yet to be extensively examined in psychiatric populations.

"Status updates" allow users to share videos, photos and written content. Preliminary findings reported that $25 \%$ of individuals sampled disclosed text-based "status updates" showing depressive-like symptoms $(2.5 \%$ met a major depressive episode 'proxy DSM criteria'). ${ }^{16}$ Momentary thoughts, emotions and topics that people discuss online can be examined using natural language processing. Such analyses have already been utilised to evaluate personality traits ${ }^{17}$, psychological stress ${ }^{18}$ and distinguishing age groups. ${ }^{19}$ Sentiment and topic analyses should be examined in the context of psychiatric disorders and whether symptoms, illness stage etc. can be differentiated.

Facebook "Likes" are statements of endorsement. Users can "like" other users' content and Facebook Pages. Research shows that personality predictions using "Likes" are more accurate that those made by friends, family members and spouses $^{20}$ and that "Likes" can predict psycho-demographic traits. ${ }^{21}$

Facebook is the world's largest photo sharing website (350 million photos uploaded daily). ${ }^{22}$ Automated picture analysis is an active area of computer science research. For example, emotional facial expressions can be measured in photographs. This promising area is still in its infancy, but photographic analysis may offer unique representations of offline behaviors.

Facebook friendship networks allow users to establish and maintain connections. Data collection can map friendship interactions and changes in social structure (e.g., sub-group clustering). Preliminary research shows that having more 
Facebook friends is associated with clinical symptoms ${ }^{23}$ and being "unfriended" can elicit negative emotions. ${ }^{24}$ Facebook users mostly interact with close friends, but users receive large amounts of content shared by their broader network through their "News Feed". When researchers reduced the amount of positive content displayed by peers on "News Feeds" this lead to more negative "status updates" by users (reducing negative content resulted in more positive updates). ${ }^{25}$ While ethically controversial ${ }^{26}$, these findings indicate that Facebook users are influenced by emotional content displayed by others.

Several caveats need addressing about social networking site research. For example, psychiatric diagnoses have been inferred by brief self-report questionnaires in non-clinical samples, wide age ranges, well-educated participants, and cross-sectional designs. ${ }^{11,29}$ While self-report measures of clinical symptoms and personality traits have been associated with increased Facebook use ${ }^{11,27,28}$, findings from studies using self-report measures must be interpreted cautiously as, for example, participants tend to overestimate use. ${ }^{12,29}$

\section{Clinical Interventions}

Many mental health-related tragedies have been documented on Facebook ${ }^{30}$ and social media. ${ }^{31}$ This should prompt a sense of urgency to address the clinical validity of such messages. Positive experiences of Facebook use have also been reported, for example patients with schizophrenia and psychosis reported that social networking sites helped them socialize and did not worsen symptoms. ${ }^{8,9}$ While such testimonies are intriguing, evidence is insufficient to determine whether Facebook has an overall positive or negative impact on mental illness. Here we propose several ways in which Facebook data could help translate evidence-based discoveries toward improving mental healthcare.

\section{Patient-Provider Interventions}

The delivery of bespoke summary measures derived from a patient's Facebook user-level data should be trialed for integration into treatment sessions. Facebook measures could help care providers identify online patterns and deviations, supplemented as graphical displays to facilitate data-centred patient-provider dialogues. Some Facebook measures could theoretically be implemented immediately (e.g., Facebook usage/activity) while other metrics will be more complex to derive (e.g., wall posting rates). 
Facebook feature-based therapies and social connection strategies need exploration. For example, Facebook picturebased and 'timeline' reminiscent therapies should be assessed given preliminary evidence that re-visiting Facebook posts/photos has a positive effect on well-being. ${ }^{29}$ This might assist with accessing autobiographical memories (e.g., for depression) and improving cognition and mood with older patients (similar to offline therapies for early dementia). Professionals could evaluate a patient's Facebook "News Feed" or comments in greater therapeutic contexts to reduce social isolation and reframe social disclosure behaviours. Facebook relationships can generate social capital by supporting

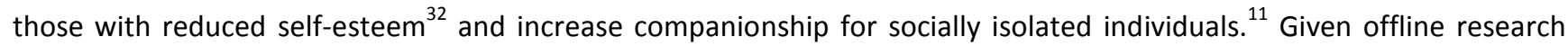
showing that socially isolated adolescents have higher rates of depression and suicidal thoughts ${ }^{5}$ these online 'stepping stones' could encourage patients to reform offline social connections.

\section{Peer-Based Interventions}

Peer-based interventions have the potential to leverage pro-social connections. ${ }^{33}$ For example, research has shown that homeless youth (a population at higher risk for mental health problems ${ }^{6}$ ) benefited from prosocial online connections, (i.e., decreased alcohol intake and fewer depression-like symptoms). ${ }^{34}$ This is especially encouraging given that $85 \%$ of homeless youth sampled could access mobile and social networking sites at least weekly. ${ }^{6}$ Network interventions that leverage companion support appear promising. ${ }^{35}$ User-level Facebook data could be superimposed onto patient grouplevel data for matching patients with similar Facebook measures, which might augment health conversations and expand their social support networks.

Unlike 'virtual patient communities', an advantage of using social networking sites, especially Facebook, is their naturalistic positioning in people's daily lives ${ }^{36}$, which addresses concerns about the limited duration of participation in virtual communities.

Using social networking sites as clinical tools for patient care holds great promise, however, this area is very much in its infancy and several caveats need addressing. Will these approaches interfere with certain illnesses or symptoms more than others? (e.g., digital surveillance-based paranoid themes). Are we equipped within mental health services to keep pace with social networking technology and how would implementation into clinical practice impact on clinician time and other costs? Social networking site interventions may prove difficult or dangerous when patients are very ill; therefore, careful consideration is needed of the possible negative effects on patient treatment. 


\section{Prediction \& Prevention}

Early detection of 'digital warning signs' could enhance mental health service contact and improve service provision. Facebook already allows users who are worried about a friend's risk of suicide to report the post ${ }^{37}$ although clinic-based social networking site interventions might be more trusted by patients. Such avenues need exploring given that many young people do not seek professional help. ${ }^{38}$ Furthermore, evidence-based research and clinical investigations should examine the feasibility and complexities of implementing social media data use as preventive measures across primary, secondary, and tertiary care.

\section{Ethical Considerations}

Social networking site ethical issues require immense scrutiny and debate ${ }^{12}$, especially in the context of mental illness and young people. ${ }^{39}$ A key ethical challenge for using social networking site data in psychiatry research and mental healthcare practice will be to ensure that vulnerable individuals have a comprehensive and sustained understanding of what participation involves and that consent is monitored throughout the patient journey (i.e., across stages of illness). Patient and public involvement should play a fundamental role in research development and care provision to gain perspectives from those needing and using mental healthcare services.

Several important unanswered ethical questions remain; for example, what best practices should be implemented for incident reporting and safeguarding of social networking site disclosures, and what obligations do care providers have when potentially threatening disclosures are made ${ }^{40}$ This is further complicated by the unknown clinical validity of statements provided by some adolescents who conceivably post false or exaggerated information on their social networking site profiles.

Another factor that must be carefully considered is public unease and adverse reactions to social media monitoring and privacy infringements, as was witnessed with the abrupt suspension of the Samaritans Radar Twitter app ${ }^{41}$, and with backlash sparked after a study accidently revealed participants' identities through the uniqueness of their data ${ }^{42}$ and manipulated "News Feeds" without consent. ${ }^{26}$ Public concerns of personal social networking site information infringements are highly justifiable, especially given the lack of transparency surrounding many questions of governance, ethics, professionalism and confidentiality. 
Patient education on social networking site safety should be incorporated into care, especially given that use is common amongst medical students and psychiatry residents ${ }^{43}$ with a predicted six-fold increase in social media use by next generation physicians. ${ }^{44}$

\section{Conclusions}

Facebook has held its position as the most popular social networking site since 2008 , but other forms of social media should be examined, including those increasingly aimed at children. It is unlikely that online social networking will decrease in popularity, so it is necessary for mental healthcare professionals and researchers to engage with them. While it is unclear how social networking sites might best be leveraged to improve mental healthcare, it holds considerable promise for having profound implications that could revolutionize mental healthcare. 


\section{References}

1. Chapman B, Raymond B, Powell D. Potential of social media as a tool to combat foodborne illness. Perspect Public Health 2014; 134(4): 225-30.

2. Facebook Inc., 2015, Retrieved on 01-02-2016 from http://newsroom.fb.com/company-info/

3. Lenhart, A. (2015). Teens, Social Media \& Technology Overview 2015. Pew Research Center. Retrieved on 01-02-2016 from http://www.pewinternet.org/2015/04/09/teens-social-media-technology-2015/

4. Christofides E, Muise A, Desmarais S. Information disclosure and control on Facebook: are they two sides of the same coin or two different processes? Cyberpsychol Behav 2009; 12(3): 341-5.

5. Bearman PS1, Moody J. Suicide and friendships among American adolescents. Am J Public Health 2004; 94(1): 89-95.

6. Rice E, Kurzban S, Ray D. Homeless but connected: the role of heterogeneous social network ties and social networking technology in the mental health outcomes of street-living adolescents. Community Ment Health J 2012; 48(6): 692-8.

7. Pedersen ER, Helmuth ED, Marshall GN, Schell TL, PunKay M, Kurz J. Using facebook to recruit young adult veterans: online mental health research. JMIR Res Protoc 2015; 4(2): e63.

8. Miller BJ, Stewart A, Schrimsher J, Peeples D, Buckley PF. How connected are people with schizophrenia? Cell phone, computer, email, and social media use. Psychiatry Res 2015; 225(3): 458-63.

9. Highton-Williamson E, Priebe $S$, Giacco D. Online social networking in people with psychosis: A systematic review. Int J Soc Psychiatry 2015; 61(1): 92-101.

10. Duggan M, Ellison NB, Lampe C, Lenhart A, \& Madden M. (2015). Social Media Update 2014. Pew Research Center. Retrieved on 01-02-2016 from http://www.pewinternet.org/2015/01/09/social-media-update-2014/

11. Wilson RE, Gosling SD, Graham LT. A review of Facebook research in the social sciences. Perspectives on Psychological Science 2012; 7:203-220.

12. Kosinski M, Matz SC, Gosling SD, Popov V, Stillwell D. Facebook as a research tool for the social sciences: Opportunities, challenges, ethical considerations, and practical guidelines. Am Psychol 2015; 70(6): 543-56.

13. Moreno MA, Cox ED, Young HN, Haaland W. Underage college students' alcohol displays on Facebook and real-time alcohol behaviors. J Adolesc Health 2015; 56(6): 646-51.

14. Backstrom L, Boldi P, Rosa M, Ugander J, Vigna S. Four Degrees of Separation. In ACM Web Science 2012: Conference Proceedings, pages 45-54. ACM Press, 2012.

15. Padrez KA, Ungar L, Schwartz HA, Smith RJ, Hill S, Antanavicius T, Brown DM, Crutchley P, Asch DA, Merchant RM. Linking social media and medical record data: a study of adults presenting to an academic, urban emergency department. BMJ Qual Saf 2015; [Epub ahead of print]

16. Moreno MA, Jelenchick LA, Egan KG, Cox E, Young H, Gannon KE, Becker T. Feeling bad on Facebook: depression disclosures by college students on a social networking site. Depress Anxiety 2011; 28(6): 447-55.

17. Park G, Kosinski M, Stillwell D, Eichstaedt J, Schwartz A, Kern P, Ungar L, Seligman M. Automatic Personality Assessment through Social Media Language. Journal of Personality and Social Psychology 2015; 108(6): 934-52.

18. Pennebaker JW, Mehl MR, Niederhoffer KG. Psychological aspects of natural language use: our words, our selves. Annu. Rev. Psychol 2003; 54: 547-77.

19. Schwartz HA, Eichstaedt JC, Kern ML, Dziurzynski L, Ramones SM, Agrawal M, Shah A, Kosinski M, Stillwell D, Seligman MEP, Ungar LH. Personality, Gender, and Age in the Language of Social Media: The Open-Vocabulary Approach. PloS ONE 2013; 8(9): e73791.

20. Youyou W, Kosinski M, Stillwell D. Computer-based personality judgments are more accurate than those made by humans. Proc Natl Acad Sci U S A 2015; 112(4): 1036-40.

21. Kosinski M, Stillwell D, Graepel T. Private traits and attributes are predictable from digital records of human behavior. Proc Natl Acad Sci U S A 2013; 110: 5802-5805.

22. Retrieved on 01-02-2016 from http://www.businessinsider.com/facebook-350-million-photos-each-day-2013-9?IR=T

23. Rosen LD, Whaling K, Rab S, Carrier LM, Cheever NA. Is Facebook Creating “iDisorders”? The link between clinical symptoms of psychiatric disorders and technology use, attitudes and anxiety. Computers in Human Behavior 2013; 29: 1243-1254.

24. Bevan JL, Pfyl J, Barclay B. Negative emotional and cognitive responses to being unfriended on Facebook: an exploratory study. Computers in Human Behaviour 2012; 28: 1458-1464.

25. Kramer AD, Guillory JE, Hancock JT. Experimental evidence of massive-scale emotional contagion through social networks. Proc Natl Acad Sci U S A 2014; 111(24): 8788-90.

26. Kleinsman J, Buckley S. Facebook study: a little bit unethical but worth it? J Bioeth Inq 2015; 12(2): $179-82$.

27. Sampasa-Kanyinga $H$, Lewis RF. Frequent use of social networking sites Is associated with poor psychological functioning among children and adolescents. Cyberpsychol Behav Soc Netw 2015; 18(7): 380-5.

28. Pantic I, Damjanovic A, Todorovic J, Topalovic D, Bojovic-Jovic D, Ristic S, Pantic S. Association between online social 
networking and depression in high school students: behavioral physiology viewpoint. Psychiatr Danub 2012; 24(1): 90-3.

29. Toseeb U, Inkster B. Online social networking sites and mental health research. Front Psychiatry. 2015; 6(36): 1-4.

30. Retrieved on 01-02-2016 from http://www.dailymail.co.uk/news/article-1344281/Facebook-suicide-None-SimoneBacks-1-082-online-friends-helped-her.html

31. Retrieved on 01-02-2016 from https://www.youtube.com/watch?v=vOHXGNx-E7E

32. Steinfield C, Ellison N, Lampe C. Social capital, self-esteem, and use of online social network sites: A longitudinal analysis. Journal of Applied Developmental Psychology 2008; 29: 434-445.

33. Laranjo L, Arguel A, Neves AL, Gallagher AM, Kaplan R, Mortimer N, Mendes GA, Lau AY. The influence of social networking sites on health behavior change: a systematic review and meta-analysis. J Am Med Inform Assoc 2015; 22(1): 243-56.

34. Rice E, Monro W, Barman-Adhikari A, Young SD. Internet use, social networking, and HIV/AIDS risk for homeless adolescents. J Adolesc Health 2010; 47(6): 610-3.

35. Kim DA, Hwong AR, Stafford D, Hughes DA, O'Malley AJ, Fowler JH, Christakis NA. Social network targeting to maximise population behaviour change: a cluster randomised controlled trial. Lancet 2015; 386(9989): $145-53$.

36. Jimison H, Gorman P, Woods S, Nygren P, Walker M, Norris S, Hersh W. Barriers and drivers of health information technology use for the elderly, chronically ill, and underserved. Evid Rep Technol Assess (Full Rep) 2008; 9: 1-1422.

37. Facebook launches new suicide prevention tool in the US. BBC Newsbeat. Retrieved on 01-02-2016 from http://www.bbc.co.uk/newsbeat/article/31641216/facebook-launches-new-suicide-prevention-tool-in-the-us

38. Eisenberg D, Golberstein E, Gollust SE. Help-seeking and access to mental health care in a university student population. Med Care 2007; 45(7): 594-601.

39. Whitehill JM, Brockman LN, Moreno MA. "Just talk to me": communicating with college students about depression disclosures on Facebook. J Adolesc Health 2013; 52(1): 122-7.

40. Jent JF, Eaton CK, Merrick MT, Englebert NE, Dandes SK, Chapman AV, Hershorin ER. The decision to access patient information from a social media site: what would you do? J Adolesc Health 2011; 49(4): 414-20.

41. Lee N. Trouble on the radar. The Lancet Technology 2014; 384: 1917.

42. Zimmer M. But the data is already public: on the ethics of research in Facebook. Ethics and Information Technology 2010; 12(4): 313-325.

43. Baer W, Schwartz AC. Teaching professionalism in the digital age on the psychiatric consultation-liaison service. Psychosomatics 2011; 52(4): 303-9.

44. Weinstein AL, Saadeh PB, Warren SM. Social networking services: implications for the next generation of physicians. Surgery $2011 ; 150(1): 15-6$.

Authors/Contributors: BI writing, re-drafting; DS, commenting, re-drafting; MK, commenting, re-drafting; PJ, commenting, re-drafting.

Conflict of interest statement: We $[\mathrm{BI}, \mathrm{DS}, \mathrm{MK}, \mathrm{PJ}]$ declare that we have no conflicts of interest.

Role of funding source and ethics committee approval: no funding was required for this article nor was any ethical approval required. 


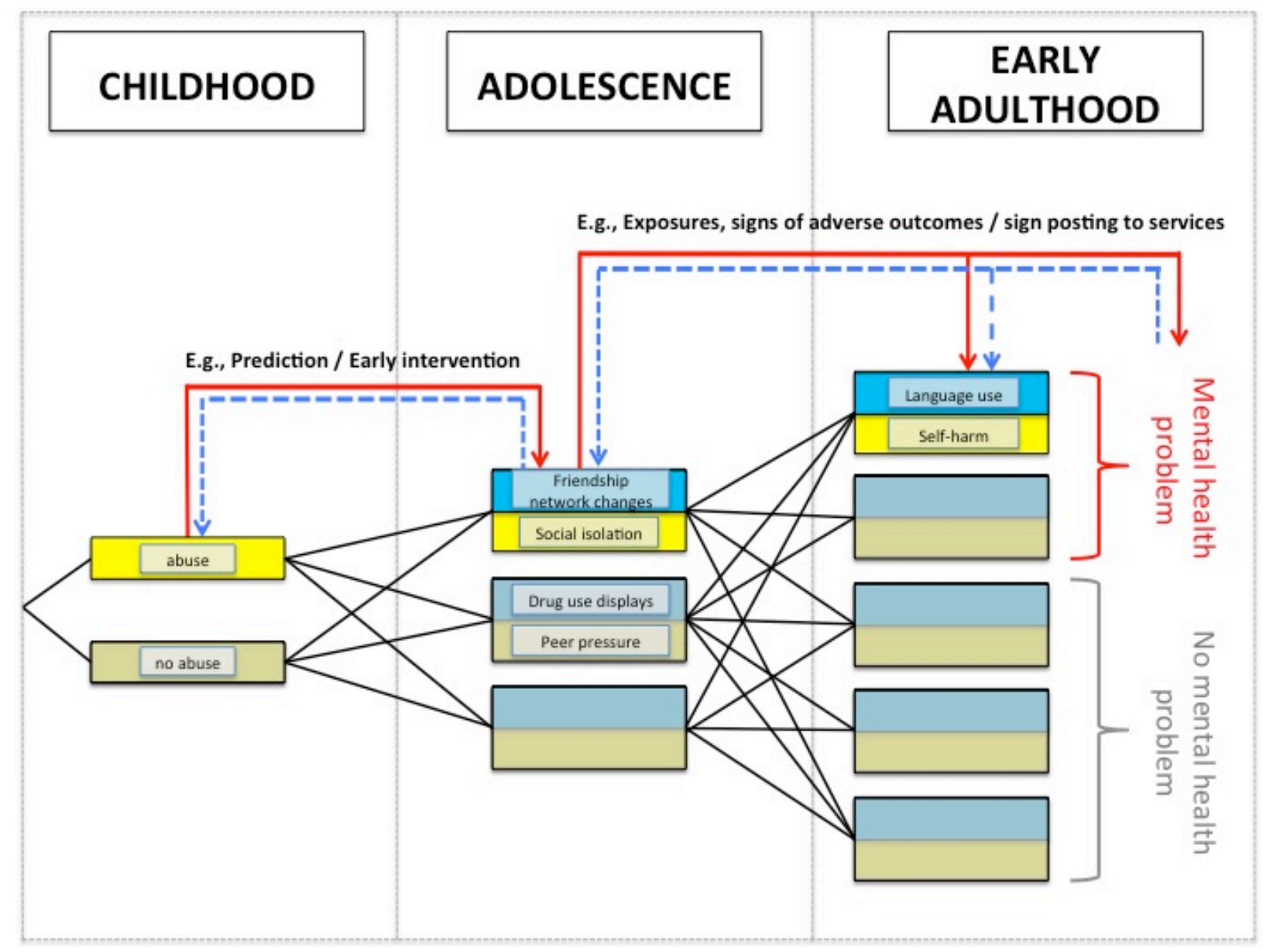

Figure 1: An online-offline longitudinal mental health framework offers opportunities to assist with evidence-based identification, intervention and possibly prediction and prevention. Facebook measures (blue boxes); offline clinical and behavioural measures (yellow boxes). 